\title{
DISPENSING WITH UNWANTED POLYSEMY: VERBAL IDIOMS AND THE LEXICON
}

\author{
JAN WIŚLICKI \\ University of Warsaw
}

\section{ABS T R AC T}

The paper focuses on verbal idioms and their place in the lexicon. I discuss their morphosyntactic properties and effects observed for copredication. The data show that verbal idioms can be neither stored as atomic items, nor can their parts be treated as polysemous, i.e. as including "standard" and idiomatic meaning. I argue that a plausible result can be achieved by combining the framework of Distributed Morphology with Chomsky's recent version of cyclic derivation. Viewed from that angle, idioms can be treated as emerging from derivational layers yielding a kind of structural coercion in the sense of Harley \& Noyer (2000).

\section{[1] INTRODUCTION}

In his recent work, Cooper (2017) treats coercion as a mean for keeping chaos easily emerging in natural languages under (partial) control. There is a plenty of effects, so the argument goes, e.g. the lack of fixed interpretation, polysemy and problems with decidability, modifying meanings by the users of language on the fly, that increase the distance between natural and formal languages. Coercion, if sufficiently regular, can be conceived of as a part of grammar ramifying these potential sources of chaos in systematic mechanisms.

Adopting to certain extent this idea, I discuss some closely related problems observed for verbal idioms (VIs) as those presented below:
a. Mary showed Peter the door. $\rightsquigarrow$ Mary dismissed Peter.
b. Mary gave Peter the cold shoulder. $\rightsquigarrow$ Mary ignored Peter/treated him in an unfriendly way.

A closer look into such expressions, especially into their morphosyntactic properties, unearths quite severe problems in assigning them the proper status in the lexicon. These primary observations give rise to further steps. First, I show that the standard coercion is not the right mechanism for resolving these complications. Second, I argue that a plausible result can be obtained at the presemantic level of computation, under a more relaxed, derivative approach to lexicon proposed by 
Alec Marantz (1996 et seq.). In this regard Marantz's lexicalization resembles to much extent coercion as presented by Cooper. The general conclusion is that VIs deliver strong arguments supporting a programmatic approach to lexicon.

The paper is organised as follows. In section [2] I present data showing conflicting properties of VIs; the data suggest that VIs should be treated as both atomic and complex. Basing on these observations, in section [3] I sketch a general theoretical background combining Marantz's idea of lexicalization with that of cyclic derivation as proposed by Chomsky (2013 et seq.). I show that the machinery naturally accounts for the effects discussed in section [2]. Finally, in section [4] I compare the offered solution with potential alternatives.

\section{[2] THE DATA: ATOMIC PROPERTIES OF VERBAL IDIOMS}

Let us start from taking a closer look at some data. What is especially puzzling from the point of view of the present discussion is that such constructions show conflicting properties. On the one hand, effects observed for movement, pronoun indexing and compositionality suggest that VIs should be treated as atomic lexical items (LIs). On the other, their morphosyntactic properties show that the grammar must secure their internal structure. I address each of the two demands in subsection [2.1] and [2.2], respectively.

\section{[2.1] Idioms and their atomic properties}

Let us first have a look at the most obvious aspect of the atomic behaviour of idioms, viz. the lack of compositionality. Parts of idioms proper are not straightforwardly compositional, either under the functional or substitutional version of compositionality (cf. Pagin \& Westerståhl 2010):

(2) $\llbracket$ Mary showed Peter the door $\rrbracket$

a. $\quad \neq \lambda z_{e} \cdot \lambda y_{e} \cdot \lambda x_{e} \cdot \operatorname{Mary}(x) \& \operatorname{Peter}(y) \& \operatorname{door}(z) \& \operatorname{showed}(x, y, z)$

b. $\quad \neq \llbracket$ Mary showed Peter the doorway $\rrbracket$

The general observation is trivial: it is not the case that show and the door pick out the action of showing predicated upon the door. Still, this does not tell anything about the source of the non-compositional character of VIs. Much more can be inferred from relations observed in syntactic derivation.

Let us start from a minor yet puzzling effect. As exemplified in (3), VIs do not allow co-indexing defined on their idiomatic parts: ${ }^{1}$

(3) a. She showed Peter the book ${ }_{1}$, but I couldn't find it $t_{1}$.

b. "She showed Peter the door ${ }_{1}$, but I couldn't find it ${ }_{1}$.

[1] Unless stated otherwise, \# marks the lack of an expected idiomatic reading. 
This fact pushes the previous observation one step further. While (2) states that VIs cannot be standardly composed from its parts, (3) shows that syntax cannot identify the idiomatic NP as an object for co-indexing.

These effects fit well with those observed for movement. A brief look shows that idioms are islands for their proper parts. First of all, they block wh-movement, as in (4):

(4) a. "What ${ }_{1}$ did Mary show Peter $t_{1}$ ?

b. "What ${ }_{1}$ did Mary do $t_{1}$ with the door?

A slightly weaker yet similar obstacle can be observed for passivization:

(5) a. "The door was shown by Mary to Peter.

The problem is more complex than the previous one because it is not the case that VIs universally block passivization. The classical example is to make headway which, while in general allowing passivization, is more restrictive w.r.t. other elements of verbal domain:

(6) a. Some real headway was made today.

b. Much headway was made on this project. (from Salzmann 2017)

c. ??Much headway on this project was made. (from Salzmann 2017)

For further details I send the reader to the vast literature on the topic (see Chomsky 1980, Hulsey \& Sauerland 2006, Salzmann 2017 and much related work). For the present purpose it will suffice to point out that passivization of VIs involving movement of their idiomatic parts is rarely possible. If it is, insertion of other constituents between idiomatic parts poses further problems.

Finally, VIs block movement to topic-marked positions. Interestingly, this applies also to adjuncts as in (7), more often than not quite flexible for that kind of operation:

(7) a. At the castle $e_{1}$, John will meet the police $t_{1}$.

b. ${ }^{\# A t}$ bay $_{1}$, John will keep the police $t_{1}$.

So, to sum up, proper parts of idioms pose serious obstacles for movement of its parts, regardless of the landing site ([Spec, CP], [Spec, TP] or [Spec, TopP]) or the category (nominal, verbal or adjunct). To close this part of discussion I will point out yet another important fact. As illustrated below, neither problems for co-indexing as in (8), nor those for movement as in (9), equally arise for nonidiomatic arguments occurring within VIs:

(8) Yesterday she showed Peter 1 the door, but today she hired him 1 again.

(9) a. Whom ${ }_{1}$ did Mary show $t_{1}$ the door? 
b. Peter was shown the door by Mary.

This fact seems to suggest that strictly local relations hold only within idioms proper, not within the whole verbal domain. Most of operations interfering in that kind of relations result in blocking the idiomatic reading.

The provisional conclusion is that VIs behave like atomic units, under the simplest approach like single LIs. Indeed, had show the door been a single lexical entry, neither of the abovementioned problems would have arisen. However, in the next subsection I discuss data showing that this cannot simply be the case.

\section{[2.2] Idioms and their structural properties}

In what follows, I am going to show that, while plausible for the abovementioned reasons, treating VIs as atomic LIs is untenable. I present two arguments, one of a purely empirical, another of a conceptual nature.

First of all, it cannot passed unnoticed that, though highly limited, nominal idiomatic parts of VIs allow merger with non-idiomatic modifiers and determiners, sometimes obligatorily:

(10) He was just pulling your leg $\rightsquigarrow$ He was just teasing you.

(11) We have made a great headway towards self-sufficiency.

(12) a. Peter kicked the proverbial bucket.

b. Peter kicked the goddamn bucket.

This class of expressions is not homogeneous and, to my knowledge, still understudied (see Zwart 2009 for some interesting comments connected with his layered, top-down approach to derivation). First, there seems to be a correlation between the type of verb and the acceptability of modifiers. Light verb constructions (take, make, get, ...) are more permissive in this regard:

a. We have made an impressive headway.

b. He took a long nap.

Second, there are interesting semantic effects hidden behind some of those examples. That is, neither of the two sentences in (12) means that Peter kicked (in the idiomatic sense of kicking) an $x$ which is a bucket (in the idiomatic sense) and that $x$ is proverbial/goddamn. Rather, the two modifiers seem to work like operators. The former looks like a metalinguistic operator marking the fact that the phrase kick the bucket is not used in its literal meaning. The latter seems to mark speaker's attitude (anger, sadness, sorrow, ...) towards Peter's death. Nevertheless, regardless of the exact semantics of such units, all the abovementioned modifiers and determiners must be somehow combined with nominals. For this 
to be possible, idioms like kick the bucket in (12) or pull someONE's leg in (10) must be syntactically structured, thus non-atomic.

The second argument is more of a conceptual character. That is, idioms show absolutely standard distribution of morphological features, such as CASE or $\varphi$ features. In the generative tradition this sort of distribution follows, at various stages depending on the exact variant of grammar, from syntactic relations. Thus for show Peter the door to be interpretable, both the door and Peter must be assigned the proper CASE. Consequently, the derivation should secure the relevant local relations between verbal heads and nominals, roughly like in (15) below (see Harley 1995 and its offshoots for a detailed discussion):

$$
\text { [Subj } \left.\left[v^{0}\left[\text { Peter }_{\text {DAT }}\left[\text { show the door }_{\text {ACC }}\right]\right]\right]\right]
$$

Otherwise the grammar can neither secure their interpretability, nor can it block overgeneration of phrases with improper distribution of CASE, e.g.:

$$
{ }^{*} \text { Mary showed to/of/for ...Peter to/of/for...the door. }
$$

So, here comes the general conclusion. Under relatively weak and widely accepted assumptions, the possibility of combining parts of VIs with determiners/modifiers as well as the distribution of morphosyntactic features show that the two effects cannot be explained if VIs are taken as atomic LIs. At least at some level of derivation they seem to behave like standard VPs.

\section{[2.3] Interim conclusion No. 1}

In this section I had a general look at some data showing a puzzling conflict. On the one hand, VIs show a typically atomic behaviour, disallowing straightforward composition, blocking movement and co-indexing its parts with non-idiomatic pronouns. While these problems would not arise had idioms been taken as atomic LIs, further data from modification and the distribution of CASE show that this is not possible. The general conclusion is that we need a machinery which is able to yield the structure of VIs and close them off within an atom.

\section{[3] LEXICON AND DERIVED ATOMS}

The simplest approach to the problems shown in [2] is to assume that the grammar must derive atoms from syntactically complex structures. One potential option is coercion: idioms could be taken as expressions derived by coercing "standard" LIs. This, however, would be problematic. Apart from the non-trivial problem of what should be the idiomatic meaning of shoulder in give SOMEONE the cold shoulder resulting from coercion of $\left\ulcorner\lambda x_{e}\right.$. shoulder $\left.(x)\right\urcorner$, there is an argument from accidental polysemy in the sense of Asher (2011). Actually, VIs behave like bank (fin- 
ancial institution and form of land) in that they do not allow copredication with its parts as taken in the idiomatic reading:

(17) a. " The bank specializes in IPOs and is steep and muddy and thus slippery. (from Asher 2011, \# marks semantic deviancy)

b. "She had found $t_{1}$ and then gave him the cold shoulder ${ }_{1}$.

This observation makes the puzzle designed so far even more complex. If copredication is the right test for the accidental/logical polysemy distinction (cf. Cruse 1986), then the "standard" and the idiomatic shoulder must have been mere homonyms. On the other hand, the analysis in section [2] showed that VIs cannot be generated as atoms. The relevant question arises, then, in what form are they stored in the lexicon.

I am going to argue that the discussed data deliver a strong argument in favour of taking lexicalization as following from syntactic derivation. The approach is conceptually cognate with Cooper's view on coercion as mentioned above. That is, one reason of introducing coercion into his semantics is that, within dialogues, users of language can create meaning of the fly (cf. Cooper 2012; 2016; 2017). Accordingly, there is a serious threat for any formal grammar to run into chaos. Coercion, rather than giving causing disturbance within natural language, may allow to keep this potential chaos under control, provided it can be shown to be sufficiently regular. I claim that there is an analogy between such presented coercion and the properly defined lexicalization resembling to some extent what Harley \& Noyer (2000) call structural coercion. Lexicalization defined in this way is a recursive syntactic operation that can be conceived of as a way grammar keeps a lexical chaos under control. The required regularity can be achieved by combining the view on lexicon as proposed by Marantz with cyclicity as proposed in the Minimalist syntax.

\section{[3.1] Lexicon in Distributed Morphology}

The idea underlying Marantz's $(1996 ; 1997)$ view on lexicon is that it should correspond to three computation-wise distinct notions:

- pure lexicon - set of morphosyntactic features relevant only for syntactic computation, and not for semantic/phonological interpretation;

- vocabulary - set of connections between LIs and phonological features;

- encyclopedia - set of connections between syntactic objects (SOs) and meanings that are irrelevant for syntactic computation.

In theories called by Marantz lexicalist, syntax combines units possessing features from all the three sets. His approach goes orthogonally to this direction. If 
there is no regularity between the size of syntactic structures and the size of noncompositional semantic units, so the argument goes, then information stored as encyclopaedic meaning must be definable for syntactic complexes:

There is a continuum between the meanings of atomic morphemes and, at least, derivationally derived words that ends abruptly at the word level...Idiomatic structures ranging from "light verb" constructions like ["take a leap", "take a leak",...] to "The shit hit the fan" show the same properties of special meanings for roots in context as do derived words. [Marantz (1997:207)]

Accordingly, Marantz takes syntax to involve two sorts of SOs. First, roots understood as carriers of conceptual information (idiosyncratic meanings assigned by encyclopedia). Second, functional heads $\left(n^{0}, v^{0}, \ldots\right)$ which assign formal features to uncategorized roots, allowing their interpretation (cf. Bobaljik 2017). Under the strictly Marantzian view, roots as such are devoid of all other features ${ }^{2}$, their role being just to enable mapping to meaningful terms in the context of functional heads, and possibly other roots (but see also Arad 2005 or Borer 2013; 2014b for non-trivially distinct approaches). Consequently, Marantz (1996) claims that at the level of syntax roots do not differ from each other. The derivation of, say, dog and cat is the same:

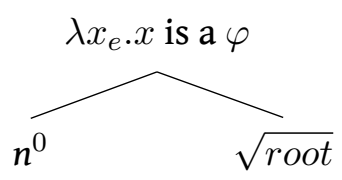

Roots appearing in the relevant syntactic context are assigned idiosyncratic information by encyclopedia (perhaps being in a sense overloaded, cf. Labelle 2014) that cannot be retrieved in the course of compositional computation. Once they are merged with functional heads, this information is inserted in the form of a full-fledged formal term. It is thus at the post-syntactic level where the system yields the meaning of cat (formally inserting the constant at the place of $\varphi$ ) as different from that of dog.

What is crucial for the present discussion is that lexicalization, rather than assumed beforehand, is determined by syntactic structures (merger of functional nodes). Nevertheless, that kind of powerful machinery opens up a wide path for overgeneralization. To avoid this, it must specify why some structures undergo lexicalization, and others do not. One candidate is cyclicity: there are numerous proposals according to which lexicalization should be coordinated with derivational cycles determining chunks ready for interpretation. If this line of reasoning, as supported by wide range of data (cf. Marantz 2007, Borer 2013; 2014a and

[2] Merchant (2018) goes event further and takes roots as devoid of all selectional properties. 
Bauke 2014, a.o.), is correct, then the account can be conceived of as a plausible constraint. That is, for lexicalization to be justified, the whole structure must meet two requirements. First, correlation between the lexicalized material and the cycle must exemplify some more general pattern of cyclicity. Second, the lexicalized structure must show cyclic properties, again defined as a part of a general architecture of cyclicity. In what follows I show that VIs do conform to the combination of lexicalization and cyclicity as defined in Chomsky's recent framework of the so-called lower phase.

\section{[3.2] Lexicalisation and syntax}

The view that LIs are in fact products of syntactic derivations, together with the result in the form of a more flexible lexicon (either as in Pustejovsky 1995 or a more traditional form) has two faces. On the one hand, it could be taken as an open path for stipulated lexicalization. Nevertheless, there is also a way for drawing an analogy between that kind of flexible lexicalization and Cooper's view on coercion as mentioned above. Lexicalization determined by syntactic structures and defined upon Marantz'a lexicon might serve a similar purpose as coercion: to allow speakers to shift "standard" meanings and build different yet regularly derivable ones. For this to be possible, the particular lexicalization must exemplify an independently motivated pattern, a 'helpful regularity' to borrow Cooper's (2017) phrase. Given the absolutely free Merge (cf. Chomsky 2008; 2018), the combinatorial operation itself is not a candidate. However, as suggested above, such a more general mechanism can be naturally formulated within the account of verbal phase as presented in Chomsky $(2013,2015)$.

It is essential for the overall view on syntax in Chomsky (2001) et seq. that derivations are sliced into cycles called phases. Chomsky $(2013,2015)$ recognizes two phases (see also Grohmann 2003; Bošković 2014, a.o. for a wider range of varieties): one responsible for building a transitive verb and its complete argument structure $\left(v^{*} \mathrm{P}\right)$, another for a full proposition (CP). Under this view, $v^{*}$ and $\mathrm{C}^{0}$ are primary phase heads $\left(\mathrm{PH}^{0} \mathrm{~s}\right)$ whose merger marks reaching the phase level. This signal triggers further steps. First, Feature Inheritance (FI) - a mechanism which, for syntax-internal reasons, must remove all features from $\mathrm{PH}^{0} \mathrm{~s}$ (cf. Richards 2007). In the strictly Chomskyan account (cf. Chomsky 2013; 2015; 2018), FI identifies the next lowest head $\left(\mathrm{V}^{0}\right.$ for $v^{*}$ and $\mathrm{T}^{0}$ for $\left.\mathrm{C}^{0}\right)$ as a goal for transmitting such features. This can be illustrated at the following schema:

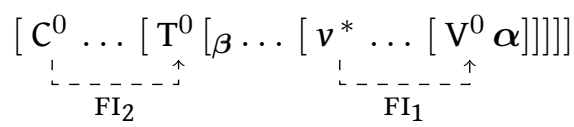

At each cycle the sister of the SO that receives the relevant features via FI, here $\alpha$ and $\beta$, becomes inaccessible for further operations. This effect is called Phase 
Impenetrability Condition (PIC; see Chomsky 2001 et seq.)

Still, the two cycles are not identical to each other. The crucial difference is that the verb is inserted as an uncategorised root and raises to $v^{*}$ where it undergoes lexicalization. Accordingly, the lower phase of the transitive verb email as presented by Chomsky $(2013,2015)$ looks as follows (irrelevant details omitted):

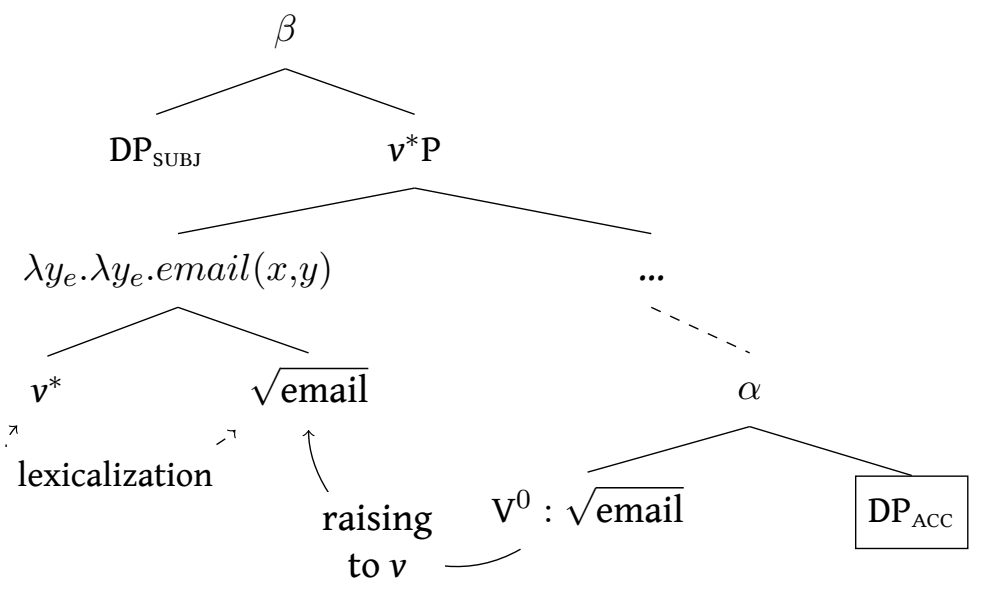

The root is lexicalized as a transitive verb (and not, say, as a nominal) after raising ${ }^{3}$ to $v^{*}$. This structure identifies $\left[v^{*}\right.$ email $]$ as the goal for post-syntactic insertion of encyclopaedic information concerning its lexicalized meaning.

As it stands, the structure in (20) cannot yield the expected results for VIs. Applied straightforwardly, it would lexicalise the verb, say show, not the whole phrase show the door as required by the idiomatic reading. Nevertheless, if syntax, as widely assumed, is the level of computation responsible for recursion (cf. Zwart 2011) and lexicalization is defined by syntactic structures, then there is no principled reason for which lexicalization could not work in a recursive way. ${ }^{4}$ One might think of a layered verbal structure as sketched in (21):

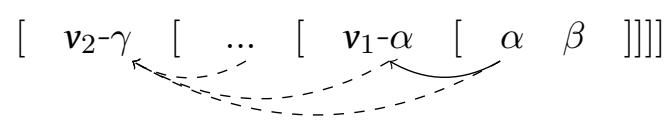

In that kind of structure successive cycles could recursively lexicalize, first, the

[3] This step is not assumed in all approaches (see Embick 2015, Alexiadou \& Lohndal 2017 and references therein for some alternative approaches). In Chomsky's recent framework based on labeling, the light head $v^{*}$ cannot be merged directly with the $\alpha$, since this would be problematic for satisfying the EPP feature on V, among others. Since this detail does not affect the discussion at hand, I leave this problem open.

[4] Actually, Harley \& Noyer (2000) explicitly state that there are no constraints concerning the size of material to be lexicalized. Some constraints might follow from the discussion in Den Dikken \& Dékány (2018). However, the discussed constraints do not apply to the present proposal, which takes the whole lower phase head to be incorporated into the higher one. 
verb $\alpha$, and next a wider scope of material $\gamma$ containing $\alpha$. This, indeed, would be a powerful tool allowing to create lexicalized semantic atoms bigger than "standard" LIs. Still, to block overgeneration lurking behind that kind of proposal it must be shown that the $v_{2}$ layer is really phasal, i.e. that it shares the relevant properties with other phasal structures. In the next subsection I show that VIs indeed meet these requirements.

\section{[3.3] Deriving verbal idioms}

With this picture in mind, let us recall two demands posed by VIs, as discussed in section [2]. First, the derivation must yield both structural and atomic (see subsection [2.1] and [2.2], respectively) properties of VIs. Second, it must account for the fact that some SOs, mostly indirect objects, occurring within VIs do not share properties of the surrounding idiomatic context. Bearing all of this in mind I propose the following strategy, basically instantiating the idea envisaged in (21). VIs are first derived as standard, extensional VPs. Next, their strictly idiomatic parts undergo another process of lexicalization, resembling in some relevant respect structural coercion in the sense of Harley \& Noyer (2000). The upper layer marks the second verbal phase. To see how this might work, consider the following structure (irrelevant details omitted):

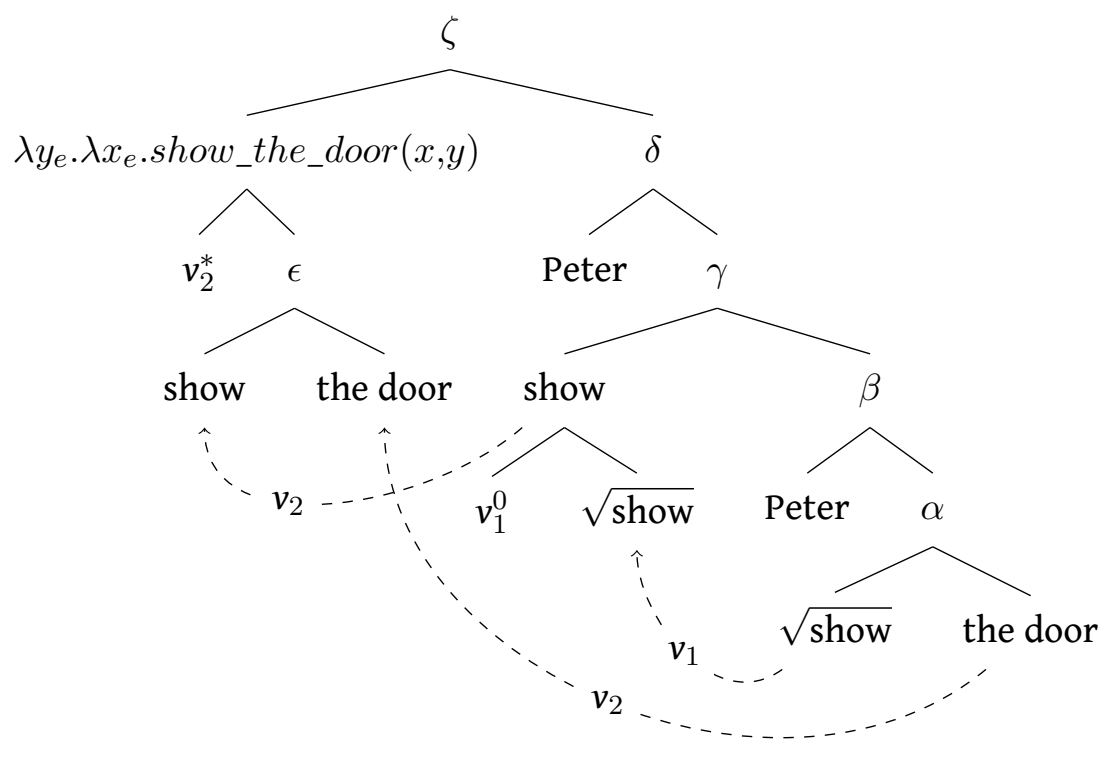

Let us have a look at the above derivation step by step. First, syntax builds the standard double object structure $\gamma$. The core of this stage is the first process of verb-formation, which is triggered by the $\sqrt{\text { show }}$-to- $v_{1}^{0}$ raising. The result is a full- 
fledged ditransitive verb show. ${ }^{5}$ Thanks to this step at the level of $\gamma$ the two NPs, i.e. the door and Peter, can be assigned CASE as standard arguments. For reasons that will become clear soon, instead of generating subject verb-internally, the non-idiomatic Peter is moved over show, that is outside the phase (to the edge). This is the last step forming the first phase.

The second phasal layer is marked by the merger of $v_{2}^{*}$, a light head which lexicalizes the incorporated material as a transitive verb. Basically, it instantiates the same mechanism as the lower one; the difference lies in the scope of lexicalization. The relevant material is that corresponding to the whole idiom. Accordingly, the door raises to $v_{2}^{*}$ together with show $\left(\sqrt{\text { show }}\right.$ pied-piped to $\left.v_{1}^{0}\right)$. The result is a transitive verb lexicalized as show the door, whose first argument is (the higher copy of) Peter.

This upper verbal layer, though derived by the same mechanism, is not trivial from the point of view of cyclic derivation. In particular, the material incorpor-

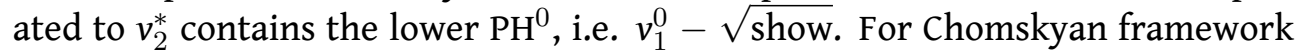
that kind of operation gives rise to the effect of phase sliding/cancellation (see Gallego 2010, as well as Bobaljik \& Wurmbrand 2013 or Epstein et al. 2016 for related ideas): raising a phasal head cancels its primary phase. In (22) this means that the root is first categorized as a ditransitive verb, but, as a result of raising and incorporation to $v_{2}^{*}$, it does not form a phase which is shipped off to the semantic and phonological interface. This fact is remarkable. Note that in this structure the only full-fledged phase is the one identified on $\left[v_{2}^{*}\right.$ show the door]. As a next step after forming the phase, all the features of the (complex) $\mathrm{PH}^{0}$ are inherited by the next lowest head, viz. $\left[v_{1}^{0}\right.$ show], as discussed in the context of (19). After FI, the sister of $\left[v_{1}^{0} s h o w\right]$, viz. $\beta$, is identified as a phase complement and thus closed off as an impenetrable whole (PIC). However, this does not apply to the higher copy of Peter which is raised to the edge of [ $v_{1}^{0}$ show].

Let us now have a look at some immediate consequences. The first result is that the structure in (22) resolves the main puzzle sketched above, viz. the mixture of atomic and complex behaviour of idioms. On the one hand, the lower verbal layer provides the complete structure for a ditransitive verb. This allows the proper distribution of morphosyntactic features as well as merger with modifiers/determiners (if acceptable), as discussed in subsection [2.2]. On the other hand, the verbal phase reached at the level of higher verbal layer accounts for the atomic character of VIs as discussed in subsection [2.1]. The crucial step is lexic-

[5] Since I focus on the problem of deriving the idiomatic predicate as a transitive verb, I draw a simplified picture of the derivation of ditransitives (perhaps it should be extended to the one fitting with the general pattern discussed by Harley 1995 and the related work). I also do not go into problems of linear ordering. The issue, especially under the copy theory of movement, is highly complicated (cf. van Urk 2018; Collins \& Groat 2018) and of a minor importance for the general architecture (cf. Chomsky et al. 2018). I assume that the syntax-phonology mapping is able to retrieve the right ordering at the level of the lower verbal layer $(\gamma)$. 
alization yielding two expected effects. First, it secures the non-compositional meaning of idioms. ${ }^{6}$ Second, it accounts for the islandhood of idiomatic parts. Note that once show and the door are incorporated to $v_{2}^{*}$, constraints on movement would require pied-piping of the whole show the door. This, in effect, blocks various types of movement of either of the two SOs, i.e. show or the door, as discussed in the context of (4)-(7). Finally, the higher level of lexicalization provides a natural explanation of the lack of copredication as shown in (17). It follows from the fact that, in the final output of derivation, there is no semantic argument in the form of idiomatic the door, just the predicate show the door, a single verbal head $v^{*}$. All of this shows that VIs indeed fit with the general pattern of Chomsky's verbal phase within a cyclic derivation.

To close this part of discussion, it is worth pointing out that these plausible effects support Marantz's view on lexicon as shaped in subsection [3.1]: syntactic derivation marks the proper points for lexicalization, instead of being fed by already lexicalized units. The data from copredication showed that there is no reason to assume any relevant connection between idiomatic and non-idiomatic the door. Accordingly, the question of how the door understood as a part of idiom can be stored in the lexicon has emerged as an especially puzzling one. Marantz's view on the lexicon, together with the Chomskyan account of verbal phase, offer an explanation. What is "stored" is a conceptual information that can become a lexicalized item within the proper syntactic structure. If properly derived, the mere fact that this structure is formally complex does not play any role. In this sense the derivation may first lexicalize the ditransitive show, and then the transitive show the door without any inconsistencies.

\section{[3.4] Interim conclusion No. 2}

In this section I applied the general Chomsky-Marantz framework to the data discussed in Section [2]. It has been shown that the puzzling properties of VIs, i.e. the fact that they must be treated as both atomic and complex, can be accounted for by making use of two crucial ideas. First, the syntax-driven view on lexicon, according to the scope of lexicalization follows from particular syntactic structures, and thus they are not fed by already lexicalized items. Second, phasal derivation thanks to which the operation of lexicalization can be defined recursively, targeting some previously lexicalized SOs. This allows to derive VIs as following neither from an extended account of lexicon which assumes polysemous units, nor from more complex compositionality, but rather from a cyclic account of lexicalization.

[6] I leave aside the problem of whether the encyclopaedic source of information required for show the door is exactly the same as that for "standard" LIs (see Embick 2015 for the relevant discussion). For the present sake it will suffice to derive VIs as lexicalized SOs in a way securing the relevant semantic and morphosyntactic effects. 
[4] IDIOMS AND THE LEXICON: THE DISCUSSION

One important result of the account presented in [3] is that it avoids non-trivial problems arising for lexicon: parts of idioms are not stored in the lexicon as variants of polysemous LIs. The crucial argument comes from copredication. If, as shown in (17), idioms block copredication, then their parts can be related with their non-idiomatic counterparts only via accidental polysemy. Nevertheless, there is a vast literature going in the opposite direction and suggesting that LIs are polysemous, so that the idiomatic reading can be obtained via composition (cf. Larson 2017, Rodrigues \& Rio-Torto 2013, a.o.). Let us then have a quick comparative look at the proposed account and potential alternatives.

First of all, any selection of the right meaning of a polysemous unit must be an additional subprocess. This automatically increases the complexity of compositionality (see Gehrke \& McNally 2017 for the relevant example and further discussion). By contrast, the proposed analysis assumes no special/additional operations. Being based on cyclicity (derivation by phases) and lexicalization as proposed within DM, it recursively applies mechanisms required anyway and supported by independent factors.

Second, moving the problem of computation of idioms to semantics hardly allows to tackle numerous morphosyntactic effects observed for such units. Some of them, such as wh-movement, topicalization or passivization were touched upon in this paper. Findlay (2017), though arguing for weakening lexical integrity, suggests that idioms should be associated (as LIs) with particular syntactic structures which secure the relevant morphosyntactic effects (e.g. passivization). ${ }^{7}$ This, however, hardly solves problems where idioms show constraints outside the idiomatic context. To illustrate, let us have a look at two interesting suffixes, -sa and $-m i$, yielding deadjectival nominals in Japanese:

$$
\begin{aligned}
& \text { omo-i } \longrightarrow \text { omo-sa; fuka-i } \longrightarrow \text { fuka-sa } \quad . . \\
& \text { heavy-ADJ } \longrightarrow \text { heavi-NMLZ; deep-ADu } \longrightarrow \text { deep-NMLZ ... } \\
& \text { 'heavy } \longrightarrow \text { heaviness; deep } \longrightarrow \text { deepness ...' }
\end{aligned}
$$

$$
\begin{aligned}
& \text { omo-i } \longrightarrow \text { omo-mi; fuka-i } \longrightarrow \text { fuka-mi } \quad \ldots \\
& \text { heavy-ADJ } \longrightarrow \text { heavi-NMLz; deep-ADJ } \longrightarrow \text { deep-NMLZ ... } \\
& \text { 'heavy } \longrightarrow \text { heaviness; deep } \longrightarrow \text { deepness ...' }
\end{aligned}
$$

As discussed by Sugioka \& Ito (2016), for VIs like kosi ga omoi (lit. '[to have] heavy hips', idiom. 'to be slow to act'), the two nominalization patterns are not equivalent:

$$
\begin{aligned}
& \text { kosi ga omo-i } \longrightarrow \text { kosi no omo-sa } \\
& \text { hips NOM heavy-ADJ } \longrightarrow \text { hips GEN heavi-NMLZ }
\end{aligned}
$$

[7] Thanks to Matthew Gotham for bringing this paper to my attention. 
lit. [to have] heavy hips; idiom. to be slow to act $\longrightarrow$ lit. the heaviness of one's hips; idiom. slowness to act

kosi ga omo-i $\longrightarrow$ kosi no omo-mi

hips NOM heavy-ADJ $\longrightarrow$ hips GEN heavi-NMLZ

lit. '[to have] heavy hips'; idiom. 'to be slow to act' $\longrightarrow$ lit. 'the heaviness of one's hips'; [no idiomatic reading]

The authors suggest that the two effects are rooted in scope differences and the way the idiom is derived. ${ }^{8}-$ sa, so the argument goes, takes scope over the whole idioms. Thus first the derivation forms the pure idiom, and then the adjective stem is attached to the nominalizing suffix - sa by head movement:

$$
\left[\left[\text { kosi no } \mathrm{t}_{1}\right]\left[\mathrm{omo}_{\uparrow}-\mathrm{sa}\right]_{\mathrm{N}}\right]_{\mathrm{NP}}
$$

By contrast, -mi does not take such a wide scope and thus blocks the idiomatic reading. If this line of reasoning is on the right track, then the analysis proposed in Section [3] correctly predicts the expected results. Lexicalization is defined on the phrase kosi no omo- and then the adjectival stem moves in order to undergo nominalization by $-s a{ }^{9}$ By contrast, $-m i$ must have been attached low, so that lexicalization would target the whole nominal kosi no omo-mi, contrary to the facts. Consequently, the proposed account allows not only to derive idioms by very general mechanisms, without additional levels of computation, but also to define further operations, like those in (27).

\section{CONCLUSION}

The main aim of the present paper was to argue in favour of lexicon understood as a source of encyclopaedic information whose insertion is determined solely by syntactic derivation. In this regard, it allows to point out certain results, as well as formulate future challenges.

Empirically, it discussed the problem of expressions that show both atomic and complex properties. It argued for a strictly derivational approach in which syntactic complexes undergo recursive lexicalization determined by particular syntactic structures. The analysis took into account both semantic (compositionality, copredication) as well as morphosyntactic (movement, agreement, CASE, nominalization) properties of verbal idioms.

On theoretic grounds, the paper delivered arguments supporting the Marant-

[8] The distinction may have semantic motivations. -mi is more constrained than the very general -sa; usually, it provides a sort of intensional state: a taste/tinge of.

[9] This might raise doubts in the context of the above account of wh-movement, which was taken to be blocked by the general principles of incorporation and movement. Note, however, that (27) exemplifies movement required by morphological reasons, not wh-movement. As such it is a natural candidate for excorporation (for the relevant discussion, see Roberts 1993, Jouitteau 2011), a.o. 
zian view of lexicon combined with Chomsky's recent account of cyclic derivation. It showed that the challenging material in the form of verbal idioms can be derived by recursive application of phasal heads, with lexicalization treated as its core effect. That kind of machinery allowed to avoid problematic assumptions concerning building blocks of idioms, and thus to economize lexicon.

The proposed approach also opens up some paths for future research. Perhaps the most far-reaching problem arising under the free Merge approach is the scope and limitations of lexicalization. Of a particular interest might be the problem of syntactic recursion and its connection with lexicalization. Viewed from this angle, it allows to raise the widely discussed problem of dynamicity of lexicon as reducible to syntactic derivations, and not to independent (lexicon-internal) operations. Finally, the paper has not touched upon the formal semantic interpretation of lexicalization conceived of as a part of syntactic derivation; I leave this problem for future research.

\section{ACKNOWLEDGMENTS}

Parts of this paper were presented at Workshop on Approaches to Coercion and Polysemy (Oslo, 2017). Critical comments from the audience, in particular Nicholas Asher, Matthew Gotham, Atle Grønn, Alexandra Spalek as well as an anonymous reviewer are gratefully acknowledged. Special thanks to Matthew and Alexandra for organizing the workshop. All errors are solely mine.

\section{REFERENCES}

Alexiadou, Artemis \& Terje Lohndal. 2017. The structural configurations of root categorization. In Leah Bauke \& Andreas Blümel (eds.), Labels and roots, vol. 128, 203-232. Walter de Gruyter GmbH \& Co KG.

Arad, Maya. 2005. Roots and Patterns: Hebrew Morpho-syntax. Dordrecht: Kluwer.

Asher, Nicholas. 2011. Lexical Meaning in Context: A Web of Words. Cambridge: Cambridge University Press.

Bauke, Leah S. 2014. Symmetry breaking in syntax and the lexicon. Amsterdam/Philadelphia: John Benjamins.

Bobaljik, Jonathan David. 2017. Distributed morphology. Oxford Research Encyclopedias: Linguistics .

Bobaljik, Jonathan David \& Susi Wurmbrand. 2013. Suspension across domains. In Ora Matushansky \& Alec Marantz (eds.), Distributed Morphology Today: Morphemes for Morris Halle, 185-198. Cambridge, MA: MIT Press. 
Borer, Hagit. 2013. Structuring sense: Volume iii: Taking form, vol. 3. Oxford: Oxford University Press.

Borer, Hagit. 2014a. The category of roots. In Artemis Alexiadou, Hagit Borer \& Florian Schäfer (eds.), The syntax of roots and the roots of syntax, 112-148. Oxford: Oxford University Press.

Borer, Hagit. 2014b. Wherefore roots? Theoretical Linguistics 40(3/4). 343-359.

Bošković, Željko. 2014. Now I'm a Phase, Now I'm Not a Phase: On the Variability of Phases with Extraction and Ellipsis. Linguistic Inquiry 45(1). 27-89.

Chomsky, Noam. 1980. Rules and representations. New York: Columbia University Press.

Chomsky, Noam. 2001. Derivation by phase. In M. Kenstowicz (ed.), Ken Hale: a life in language, 1-52. Cambridge, MA: MIT Press.

Chomsky, Noam. 2008. On Phases. In Robert Freidin, Carlos Otero \& Maria Luisa Zubizarreta (eds.), Foundational Issues in Linguistic Theory. Essays in Honor of JeanRoger Vergnaud, 133-167. Cambridge, MA: The MIT Press.

Chomsky, Noam. 2013. Problems of Projection. Lingua 130.33-49.

Chomsky, Noam. 2015. Problems of projection: extensions. In Elisa Di Domenico, Cornelia Hamann \& Simona Matteini (eds.), Structures, strategies and beyond: Studies in honour of adriana belletti, 1-16. John Benjamins.

Chomsky, Noam, Ángel J. Gallego \& Dennis Ott. 2018. Generative Grammar and the Faculty of Language: Insights, Questions, and Challenges. Catalan Journal of Linguistics .

Collins, Chris \& Erich Groat. 2018. Distinguishing Copies and Repetitions. Ms .

Cooper, Robin. 2012. Type theory and semantics in flux. In Ruth Kempson, Tim Fernando \& Nicholas Asher (eds.), Handbook of the philosophy of science, philosophy of linguistics, vol. 14, 271-323. Oxford: Elsevier.

Cooper, Robin. 2016. Frames as records. In Annie Foret, Glyn Morrill, Reinhard Muskens, Rainer Osswald \& Sylvain Pogodalla (eds.), Formal grammar, 3-18.

Cooper, Robin. 2017. Coercion in languages in flux. Presentation: Workshop on approahes to Polysemy and Coercion.

Cruse, D Alan. 1986. Lexical semantics. New York: Cambridge University Press. 
Den Dikken, Marcel \& Éva Dékány. 2018. A restriction on recursion. Syntax 21(1). 37-71.

Embick, David. 2015. The Morpheme: A Theoretical Introduction. Berlin: Walter de Gruyter.

Epstein, Samuel D, Hisatsugu Kitahara \& Daniel Seely. 2016. Phase cancellation by external pair-merge of heads. The Linguistic Review 33(1). 87-102.

Findlay, Jamie Y. 2017. Multiword expressions and lexicalism: the view from lfg. In Proceedings of the 13th Workshop on Multiword Expressions (MWE 2017), 73-79.

Gallego, Ángel J. 2010. Phase Theory. Amsterdam/Philadelphia: John Benjamins.

Gehrke, Berit \& Louise McNally. 2017. Idioms and the syntax/semantics interface of descriptive content vs. reference. MS.

Grohmann, Kleanthes. 2003. Prolific Domains. On the Anti-Locality of Movement Dependencies. Amsterdam: John Benjamins.

Harley, Heidi. 1995. Subjects, Events and Licensing. Massachusetts Institute of Technology $\mathrm{PhD}$ dissertation.

Harley, Heidi \& Rolf Noyer. 2000. Formal versus encyclopedic properties of vocabulary: Evidence from nominalizations. In Bert Peeters (ed.), The lexiconencyclopedia interface, 349-374. Amsterdam: Elsevier.

Hulsey, Sarah \& Uli Sauerland. 2006. Sorting out Relative Clauses. Natural Language Semantics 14(2). 111-137.

Jouitteau, Mélanie. 2011. Post-syntactic Excorporation in Realizational Morphology : Breton Analytic Tenses. In Andrew Carnie (ed.), Formal approaches to celtic linguistics, 115-142. Newcastle: Cambridge Scholar Publishing.

Labelle, Marie. 2014. Roots in models of grammar. Theoretical Linguistics 40(3-4). 401-414.

Larson, Richard K. 2017. On "Dative Idioms" in English. Linguistic Inquiry 48(3). 389-426.

Marantz, Alec. 1996. "Cat" as a phrasal idiom: Consequences of late insertion in Distributed Morphology. MS. MIT.

Marantz, Alec. 1997. No Escape from Syntax: Don't try Morphological Analysis in the Privacy of Your Own Lexicon. University of Pennsylvania Working Papers in Linguistics 4(2). 201-225. 
Marantz, Alec. 2007. Phases and words. In S.-H. Choe (ed.), Phases in the Theory of Grammar, 191-222. Seoul: Dong In.

Merchant, Jason. 2018. Roots don't select, categorial heads do:lexical-selection of pps may vary by category. Ms., University of Chicago .

Pagin, Peter \& Dag Westerståhl. 2010. Compositionality I: Definitions and variants. Philosophy Compass 5(3). 250-264.

Pustejovsky, James. 1995. The generative lexicon. Cambridge, MA: MIT Press.

Richards, Marc D. 2007. On feature inheritance: An argument from the phase impenetrability condition. Linguistic Inquiry 38(3). 563-572.

Roberts, Ian. 1993. Verbs and Diachronic Syntax: A Comparative History of English and French. Dordrecht: Springer.

Rodrigues, Alexandra Soares \& Graca Rio-Torto. 2013. Semantic coindexation: evidence from portuguese derivation and compounding. In Pius ten Hacken \& Claire Thomas (eds.), The Semantics of Word Formation and Lexicalization, Edinburgh: Edinburgh University Press.

Salzmann, Martin. 2017. Reconstruction and Resumption in Indirect $A^{\prime}$-Dependencies: On the Syntax of Prolepsis and Relativization in (Swiss) German and Beyond, vol. 117. Berlin: De Gruyter Mouton.

Sugioka, Yoko \& Takane Ito. 2016. Derivational affixation in the lexicon and syntacx. In Taro Kageyama \& Hideki Kishimoto (eds.), Handbook of Japanese Lexicon and Word Formation, 347-386. Berlin: De Gruyter Mouton.

van Urk, Coppe. 2018. Pronoun copying in Dinka Bor and the Copy Theory of Movement. Natural Language \& Linguistic Theory 36(3). 937-990.

Zwart, Jan-Wouter. 2009. Prospects for top-down derivation. Catalan Journal of Linguisitcs 8. 161-187.

Zwart, Jan-Wouter. 2011. Recursion in language: A layered-derivation approach. Biolinguistics 5(1-2). 043-056.

AUTHOR CONTACT INFORMATION

Jan Wiślicki

University of Warsaw

jan.wislicki@gmail.com 